\title{
After Babel Revisited: On language and Translation. In Memoriam George Steiner (1929-2020)
}

\author{
By Hans-Harry Drößiger*
}

On February 3, 2020, one of the most interesting scholars in humanities, especially in literary research and translation studies, died: George Steiner. Sometimes labelled as a genius, sometimes as someone who was always outside the mainstream and acting as an inconvenient thinker, he did his part in the humanities in a fresh and in a provocative way. The following article wants to shed some light on his basic writing entitled After Babel, originally published in 1975 and reviewed by himself in 1992. In doing so, this article is about to honour him for his challenging statements, insights and discussion on language and translation to be not forgotten by recent and future generations of researchers.

Keywords: George Steiner, language, translation, theory of translation, contiguity.

We are able to say so fantastically much more than we would need to for purposes of physical survival. We mean endlessly more than we say

(Steiner 1998: 296).

\section{Introduction}

First published in 1975, this volume by George Steiner gained appreciation and interest amongst scholars in the world because of its fresh, lively and competent description of translation problems and issues, not only for his time. Thus, this book requires our full attention because of its fascinating range of thoughts on language, translation and translation theory. Excerpts from the contemporary press in the scholarly world from the back cover of that edition I own, may highlight the value the book deserves even today. M. Cranston from the Sunday Times wrote: 'Translation...has long needed a champion, and at last in George Steiner it has found a scholar who is a match for the task.' Or, Donald Davie from Times Literary Supplement pointed out: 'He is saying things we cannot afford not to take note of...I greatly admire the intellectual venture which the book represents.'

Facing the situation in theory of translation studies and of linguistics in our present days of the $21^{\text {st }}$ century, there is still a need for 'a champion' of our subjects. Maybe, George Steiner can lead us to more scholarship for mastering the challenges of the present and the future. Thus, hopefully, in this essaylike article the reader will find arguments to handle language and translation in a manner they deserve.

${ }^{*}$ Professor and Senior Researcher, Vilnius University, Lithuania.

https://doi.org/10.30958/ajp.7-4-1

doi=10.30958/ajp.7-4-1 
After Babel opens a wide-scaled interpretation of the essence of language, literature and translation of the past, the present and the future of at least the entire human mankind. Of course, a reader's expectations may aim at language and what is related to it, for example literature and other forms of arts, cognition and communication, society and community, language research and translation as process and result including the scholars' and practitioners' activities, behaviour and attitudes. All that is clear, yet there is more to After Babel. It encompasses phenomena like universals and cultural boundness experienced as commons and diversities amongst and between the people in the world. It enlightens us to be able to more deeply think of and reflect on our recent activities to get prepared for the future by comprehending our past.

The most central theme announced and alluded by the book's title is Language. From there, set as the core term, in this retrospective, we will discover terms and topics orbiting around this central point. According to this, the article is divided into five sections aiming at Steiner's most interesting outlines and statements to bring them once again into the focus of scholarly discussion, starting with "Language", followed by "Translation" and "Theory of translation". Phenomena of special interest from Steiner's monograph are outlined in "Palimpsests, metaphor, and contiguity: towards a new conception of translation". The paper will be closed-up with "Instead of conclusions: an outlook". Some may put another term or concept into the central position. However, logical nomenclatures and hierarchies will not always correspond to the intentions of After Babel. Thus, all selected quotes from this book, all commentary to them, and all other statements are in the author's full responsibility.

Technically, in this article numerous quotes pinpointing Steiner's major ideas are necessary. To keep the article focused on his opinions and outlines and to achieve a coherent text flow, quotes from other scholarly papers will mostly appear in footnotes.

\section{Language}

One of the major questions Steiner is looking for an answer is the reason for the manifoldness of human languages. In the preface of the last edition revised by himself, he points out:

Why should homo sapiens sapiens, genetically and physiologically uniform in almost all respects, subject to identical biological-environmental constraints and evolutionary possibilities, speak thousands of mutually incomprehensible tongues, some of which are set only a few miles apart (p. xiii)?

And there is more to this diversity of human languages, reflected not only in several religions, because

there is no mythology known to us in which the fragmentation of some initial single language (the Adamic motif) into jagged bits, into cacophony and 
incommunicado, has not been felt to be a catastrophe, a divine chastisement on some opaque motion of rebellion or arrogance in fallen man (p. xiii).

Considering manifoldness and diversity of languages is one aspect, the other one is to ask what all those languages have in common that we might take as a starting point for developing a practicable and reliable perspective of translation. Steiner sees commons in the functions and functioning of languages, especially concerning the interplay of language and thought, by referring to Leibniz and Vico ${ }^{1}$ stating

that language is not the vehicle of thought but its determining medium. Thought is language internalized, and we think and feel as our particular language impels and allows us to do ... that man enters into active possession of consciousness, into active cognizance of reality, through the ordering, shaping powers of language (p. 78).

Steiner devoted himself to W.v. Humboldt's conviction 'that language is the true or the only verifiable a priori framework of cognition' (p. 85 - italics in original). Two interesting ideas in this brief quote shall be emphasized. First, the methodological one, namely 'verifiable', which shall lead us to an attitude after which a serious research into language and all corresponding phenomena can only be conducted by grounding on large-scale linguistic material because this is the only way to approach thought and cognition. Second, the theoretical one, namely 'a priori', which means that language due to its materialized experience (speech, writing) and their interrelations to thoughts solely give researchers reasons for exploring the world of cognition. A reason to all of this we can see, according to Steiner, in the assumption that 'the similarities between men are finally much greater than the differences' and 'that which is in fact linguistically and culturally most remote may, at moments, strike us as most poignant and cognate to our own consciousness' (p. 372).

The power of this mutual determination of language and thought is a common ground for each language in the world, it is the reason for being able to communicate including translation because of the simple but mighty capability of any language to structure our thought as well as the world we are living in. Steiner calls this quality of language 'dynamic mentalism':

language organizes experience, but that organization is constantly acted upon by the collective behaviour of the particular group of speakers (p. 91).

All in all, a triadic model can be seen by putting the given ideas together:

\footnotetext{
${ }^{1}$ Bibliographical information to sources Steiner is quoting or referring to see Steiner (1998).
} 
Figure 1. Triad \# 1

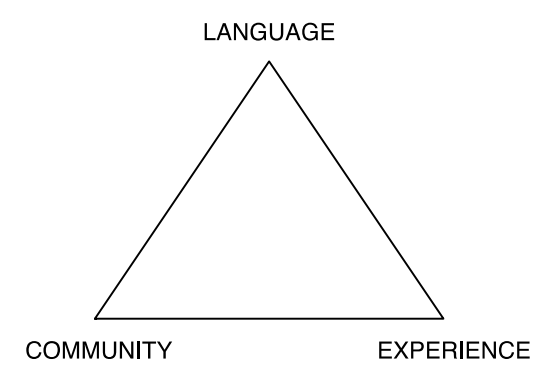

Source: visualized according to Steiner: 91

To make this capability of 'ordering, shaping' applicable for translation works will be the real task for scholars and researchers into languages and translation.

Our perception of language (and of course not only that) is what makes the essence of it. However, this perception does not always follow or not always aim at "axiomatic structures". It is the unexpected, the newly coined form, expression and content that makes language and translation research complicated as well as challenging. Steiner sees more in this special quality of language.

But it is its great untidiness that makes human speech innovative and expressive of personal intent. It is the anomaly, as it feeds back into the general history of usage, the ambiguity, as it enriches and complicates the general standard of definition, which give coherence to the system. A coherence, if such a description is allowed, 'in constant motion'. The vital constancy of that motion accounts for both the epistemological and psychological failure of the project of a 'universal character' ( $p$. 213).

It is not only the chance to put the historical and the actual character of language together, it is also the idea of a 'constant motion' that deserves our highest attention. If all those characteristics of language as 'anomaly' and 'ambiguity' that construct a coherence in the system of language, then such kinds of strangeness tend to become the basic quality of language. And if a 'vital constancy of motion' can be assumed, then the coherence of the system of language grounds in contiguity. We can only be innovative, creative and expressive in using our language if we realize the contiguous character of language by taking chances every time and everywhere to modify our point of view, to change perspectives expressing concepts and meaning.

Yet, there is more to this 'vital constancy of motion' because this concept allows us to grasp into other spheres by exploring and experiencing the full power of language.

We literally carry inside us, in the organized spaces and involutions of the brain, worlds other than the world, and their fabric is preponderantly, though by no means exclusively or uniformly, verbal ... But whatever their bio-sociological origin, the uses of language for 'alternity', for mis-construction, for illusion and play, are the greatest of man's tools by far (p. 234). 
Such phenomenon, called by Steiner 'alternity' including its sub-phenomena, like 'mis-construction', which might be errors or mistakes, respectively, 'illusion', which can appear in all forms depicting not our 'real world', 'play', which may lead to all forms and kinds of wit and humour, ground in what Steiner above has called 'vital constancy of motion', which I will call principles of contiguity. These principles keep our language alive, open it for new development, for innovation since the infinity of thinking seeks to find a tool that can handle that boundlessness of thoughts by giving it a form that others can perceive and comprehend.

Man's sensibility endures and transcends the brevity, the haphazard ravages, the physiological programming of individual life because the semantically coded responses of the mind are constantly broader, freer, more inventive than the demands and stimulus of the material fact (p. 238).

By understanding those 'principles of contiguity' it will become clear what amount of work a translator is facing while doing his/her job.

\section{Translation}

Not in the beginning of his book, though not too late, Steiner asks that question we are all interested in:

Suppose we put the question in its strongest form: 'what ... is translation?'; 'how does the human mind move from one language to another?' What sort of answers are being called for (p. 293)?

Although before and after George Steiner's book many scholars, writers, philosophers and representatives of some more kinds of human (professional) occupation had something to say about translation, in this honouring contribution to George Steiner, we want to reactivate his view on translation. It begins already in the preface (as mentioned above) by putting translation into relations to other human phenomena, which makes this first approach to understand translation so important:

There had been no ordered or detailed attempt to locate translation at the heart of human communication or to explore the ways in which the constraints on translatability and the potentialities of transfer between languages engage, at the most immediate and charged level, the philosophic enquiry into consciousness and into the meaning of meaning (p. ix-x). ${ }^{2}$

After we got this, three terms (or concepts) can be highlighted and visualized: translation, communication, and consciousness. These three concepts interdependently interact, they create some sort of unity, which may make up

\footnotetext{
${ }^{2}$ There is more to the quote. The closing-up phrase seems to be an allusion to Charles Kay Ogden and Ivor Armstrong Richard's paper The Meaning of Meaning (1923), in which a first triadic model in semiotics was presented.
} 
humans' most basic factor of existence. As a triad (see Figure 2), the model describes best what and who we are. In more modern terms and considering our freedom to interpret Steiner's outlines, we may call the components of this triad 'language', 'communication', and 'cognition'. There is good reason for renaming the given three concepts because Steiner quite clearly takes all linguistic communication, i.e. all use of languages, as a form of translation.

Figure 2. Triad 2

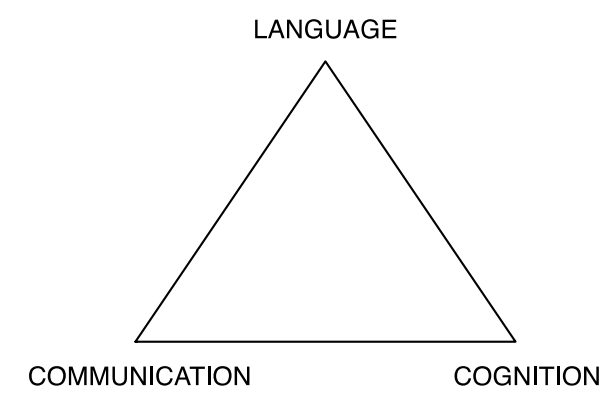

Source: Author

Although George Steiner uses this idea of a triad, in the volume several definitions or definition like outlines on 'translation' appear, each time focusing on other aspects or displaying a certain perspective to it. A first closer approach to the term 'translation' seems to be somewhat formalistic but nevertheless instructive in several ways:

The schematic model of translation is one in which a message from a sourcelanguage passes into a receptor language via a transformational process. The barrier is the obvious fact that one language differs from the other, that an interpretative transfer, sometimes, albeit misleadingly, described as encoding and decoding, must occur so that the message 'gets through'. The same model — and this is what is rarely stressed-is operative within a single language. But here the barrier or distance between source and receptor is time (p. 29).

From the given quote, a visualization is possible which covers five components of such a 'schematic model':

Figure 3. A Five Components Model of Translation

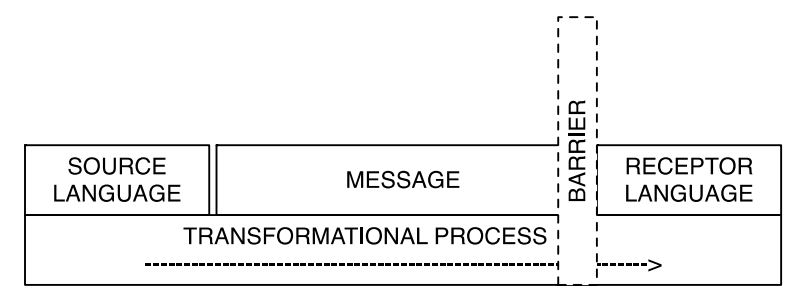

Source: visualized according to Steiner: 29 
However, if Steiner talks about an intralingual process of translation that grounds on time (as a concept), then, logically, for an interlingual process of translation the concept time should be accompanied by the concept space.

For the scenario of an intralingual translation, George Steiner focuses on semantics as the responsible instance, or shall we now say as the 'barrier', that has to be considered by the 'translator within':

Words rarely show any outward mark of altered meaning, they body forth their history only in a fully established context (p. 29).

And there is more to meaning as a subject to semantics, which can be taken as a certain form, if not the most important one, of the already mentioned 'barriers': humans' intentions. Taking politics as an example and referring to a famous scholar in politics from the past, we may understand that not only time and space set some sort of barrier before a translation might have been conducted, the human factor, namely intentions, work as such a barrier, or perhaps we may call this a filter:

Machiavelli noted that meaning could be dislocated in common speech so as to produce political confusion (p. 35).

To bring all the factors and components together, we shall modify Figure 3:

Figure 4. Another Five Components Model of Translation

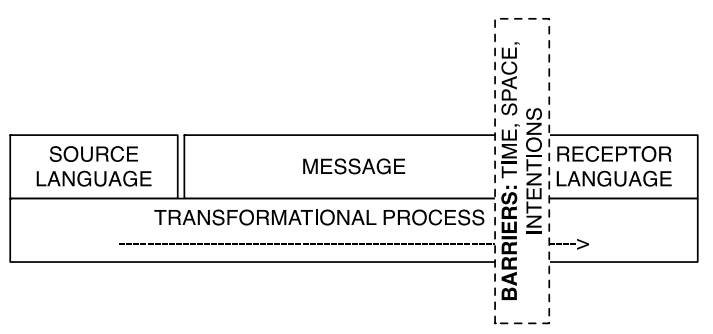

Source: visualized according to Steiner: 29,35

More thoroughly, Steiner again refers to the intralingual and interlingual plots concerning translation but always seeing a close interrelationship between language and translation:

I have been trying to state a rudimentary but decisive point: interlingual translation is the main concern of this book, but it is also a way in, an access to an inquiry into language itself. 'Translation', properly understood, is a special case of the arc of communication which every successful speech-act closes within a given language. On the inter-lingual level, translation will pose concentrated, visibly intractable problems; but these same problems abound, at a more covert or conventionally neglected level, intra-lingually ... In short: inside or between languages, human communication equals translation. A study of translation is a study of language ( $\mathrm{p}$. 48-9 - italics in original). 
One of the crucial problems in translation is what we may call 'tacit knowledge', or as Steiner puts it:

There is an acute understanding, essential to any treatment of communication within and between languages, of the ways in which a text may conceal more than it conveys (p. 64).

Consequently, if we confirm the existence of this 'tacit knowledge' (sometimes called connotations, background knowledge, or 'read between the lines'), we can imagine how difficult and challenging the work of a translator will be. Being aware of 'tacit knowledge' in both languages involved in a translation process, a translator faces multiple ways to solve translation problems, especially in those cases when linguistic items or structures 'convey' the untold but presupposed information. Admittedly, we may observe this in almost all instances of names, proper names, culture-bound words, and some unique features of any given language, or in the case of intralingual translation of any language variant. Though, there is another effect of 'tacit knowledge':

The translator enriches his tongue by allowing the source language to penetrate and modify it. But he does far more: he extends his native idiom towards the hidden absolute of meaning (p. 67).

Is that so? Does the translator really enrich their mother language while translating? Steiner sees in the case of 'background' or 'tacit' knowledge an ensemble of components that might cause huge difficulties translating a text. Additionally, to previously mentioned sequences from Steiner's book, the term 'implicit sense' appears.

The translator must actualize the implicit 'sense', the denotative, connotative, illative, intentional, associative range of significations which are implicit in the original, but which it leaves undeclared or only partly declared simply because the native auditor or reader has an immediate understanding of them (p. 291).

As we can see, Steiner has compiled such an ensemble of components of which the background (tacit or implicit) knowledge consists, determined by a crucial constituent of background knowledge that is meaning. Possibly, this is one of those explanations of background knowledge in one place that suits best for the framework of translation in theory and practice. The 'range of significations' sets up a quite different comprehension of 'meaning' or 'semantics' as a phenomenon which derives from humans' linguistic, cognitive and communicative experience. In this sense, Steiner's ideas go far beyond other descriptions or theories of meaning/semantics. ${ }^{3}$

\footnotetext{
${ }^{3}$ An overview to other theories or concepts of meaning can be found in Geerarts (2010): 'Componential analysis provides a descriptive model for semantic content, based on the assumption that meanings can be described on the basis of a restricted set of conceptual building blocks - the semantic 'components' or 'features'. Componential analysis was developed in the second half of the 1950 s and the beginning of the 1960s by European as well as American linguists, largely
} 
Figure 5. Components of Meaning

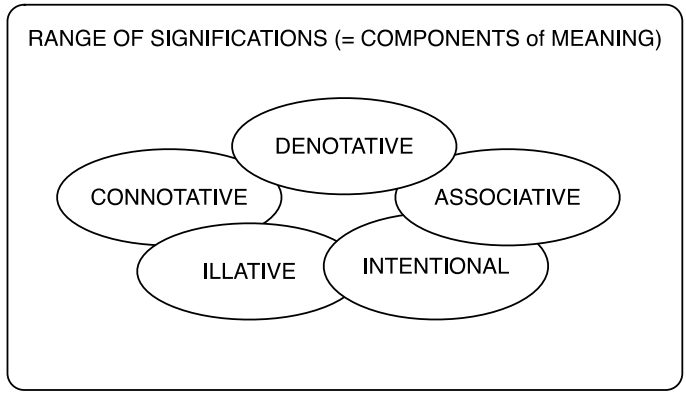

Source: visualized according to Steiner: 291

Thus, it seems to be logical, in Steiner's words, doing a translation is a process of losses because, even by hardest endeavours, a translator will not reach a perfectly matching result in a target language.

In the 'transference' process of translation, the inherence of meanings, the compression through context of plural, even contradictory significations 'into' the original words, get lost to a greater or lesser degree (p. 291).

Lastly, processing background knowledge while translating will have an impact on the development of languages, as we can see in our present days in forms of globalization when English language seems to widely spread all over the world and influencing almost all national languages. Unfortunately, those influences might lead to an imposition of English regarding language and translation research to all possible extents including terminology, foundation of theory etc. (see also p. 245). Thus, Steiner can ask a question:

Might it be that the transformational generative method is forcing all languages into the mould of English, as much seventeenth-century grammar endeavoured to enclose all speech within the framework of classical Latin (p. 112)? ${ }^{4}$

independently of each other. Although both find a common inspiration in structural phonology, componential analysis in Europe grew out of lexical field theory, whereas in the United States it originated in the domain of anthropological linguistics' (Geeraerts 2010: 70). Both approaches-the European as well as the American-ground on distinctive features in meaning related to the idea of componential analysis. 'On this approach, an account of the structural relations within the vocabulary of a language requires a componential analysis of every word, together with a set of rules... The exact nature of semantic components, and their significance, depends heavily on the theory of which they form part' (Cruse 2012: 160). From Steiner's point of view, not a theory dictates what semantic components might be but humans' communicative experience. Thus, all components of meaning are understood as complements one to each other, which makes the difference to purely deductive-theoretical approaches.

${ }^{4}$ This danger was thematised by other famous scholars of language and translation research as for example Snell-Hornby who states that 'there has been a disquieting trend in recent years for English to be used, not only as a means of communication, but also as part of the object of discussion...English publications frequently have a clear Anglo-American bias, and what are presented as general principles of translation sometimes prove to be limited to the area under discussion and to be caused by the specific status of English...Conversely, contributions 
Steiner concludes that there is more to the differences between languages.

Dissimilarities between human tongues are essentially of the surface. Translation is realizable precisely because those deep-seated universals, genetic, historical, social, from which all grammars derive can be located and recognized as operative in every human idiom, however singular or bizarre its superficial forms. To translate is to descend beneath the exterior disparities of two languages in order to bring into vital play their analogous and, at the final depths, common principles of being (p. 76-7).

In other words, it seems that all languages as that one form to express what all human communities, societies, nations need to express, ground on the same principles, or as Steiner names it 'deep-seated universals'. Assuming this, we might say that translation is a way to give a language a mode to express what once has been said in another language. Those 'deep-seated universals' have nothing to do with the artificially constructed deep-structure principles of any form of transformational or generative grammars. The demand to go deeper than linguistic surfaces and even deeper than so-called 'deep structures' seems to be essential to translators:

Translators have left not only a great legacy of empirical evidence, but a good deal of philosophic and psychological reflection on whether or not authentic transfer of meaning between languages can take place ... To know more of language and of translation, we must pass from the 'deep structures' of transformational grammar to the deeper structures of the poet (p. 114).

Sometimes Steiner uses alternative designations for 'translation'. Just those changes of names make a principle of contiguity obvious, the change of perspective. Thus, Steiner says that

the most banal act of interlingual conveyance ... involves the entire nature and theory of translation. The mystery of meaningful transfer is, in essence, the same when we translate the next bill of lading or the Paradiso. None the less, the working distinction is obvious and useful. It is the upper range of semantic events which make problems of translation theory and practice most visible, most incident to general questions of language and mind (p. 265-6).

Taking three different terms - interlingual conveyance, translation, transferto describe and express one idea is not only a matter of expressing himself stylistically varied, it is a signal for that one principle of contiguity, namely perspectivation $^{5}$ and perspective as its complement. Approaching the concept of

written in languages other than English and on topics outside Anglophile interests tend to be ignored or over-simplified' (2006: ix-x).

${ }^{5}$ Perspectivation as a term introduced by Graumann and Kallmeyer in 2002 is about to give the more widely used term perspective a complement to emphasize the relation between process - the perspectivation - and its result - the perspective - and as a common cognitive and communicative practice as well. As Graumann \& Kallmeyer suggest, both perspective and perspectivation are founding instances of any discourse. 'The study of perspectivation poses questions with respect to the role that communication of perspectives plays in text and interaction, and what important 
'translation' from different points of view, from distinguishing angles opens ways for a more precise understanding of the core concept, in this case of translation. However, changes of perspective not only work regarding a theory but also in practical translation work, as we will see below.

Additionally, to all the rational approaches to translation, Steiner finally includes an evaluative and emotional statement on translation by distinguishing between 'negative' and 'positive' ones which might be explained as a certain form of 'mistaking'.

Poor translation follows on negative 'mistaking': erroneous choice or mechanical, fortuitous circumstance have directed the translator to an original in which he is not at home... Positive 'mistaking' on the contrary generates and is generated by the feeling of at-homeness in the other language, in the other community of consciousness (p. 398-9).

To close-up this section, we will return to its opening quote from Steiner's book, page 293, to find a way to answer that 'strongest form' of a question: What is translation? Steiner's way to answer the question seems to be enigmatic, yet his answer reflects the contemporary situation in translation studies:

What must be established for such answers to be plausible or, indeed, possible? The theory and analysis of translation have, until now, proceeded as if we knew, or as if the knowledge needed to make the question nontrivial were foreseeable given a reasonable time span and the current rate of progress in psychology, linguistics, or some other authentical 'sciences'. I believe, on the contrary, that we do not know with any great precision or confidence what it is that we are asking and, concomitantly, what meaningful answers would really be like (p. 293).

Several things will be clear for our present-day approaches to translation in theory and practice. That is to be careful with a so-called 'final' statement on translation, that is also to be open for ideas and conceptions from other scholarly branches than linguistics and translation studies that deal with language and translation, that is, finally, to have a good sense for the still undiscovered and undetected characteristics of language, community, and thought.

\section{Theory of Translation}

Steiner very harshly states that a theory (or even theories) of translation are hard to find because of the scholars' attitude which might be characterized as byzantine:

strategies of perspectivation one can observe in different contexts. For the analysis of human strategies of orientation in space and time spatial reference ... proved to be of primordial interest (Weissenborn \& Klein 1982). From here it is only a short step to the analysis of referential movements in texts (Klein \& Stutterheim 1989) and its interpretation as representation of perspectival moves' (2002: 5). Bibliographical information to the sources used by Graumann \& Kallmeyer see in their article. 
There are, most assuredly, and pace our current masters in Byzantium, no 'theories of translation'. What we do have are reasoned descriptions of processes. At very best, we find and seek, in turn, to articulate, narrations of felt experience, heuristic or exemplary notations of work in progress. These have no scientific status (p. xvi). ${ }^{6}$

This highly critical offense to colleagues working in the fields of linguistics and translation will surely earn at least a lack of understanding or to the worst will meet with disapproval. Though we still have to ask ourselves what went wrong in our scholarly work that there is no serious progress in developing theory, no reliable achievements creating a system of terms, too much anecdotalism in describing linguistic and translational phenomena ${ }^{7}$ and so forth. One good reason for all these shortcomings can be named as follows:

The dilemma seems to me of central importance precisely in an age in which deconstructive criticism and self-advertising scholarship dismiss texts as 'pre-texts' for their own scavenging (p. xvi-xvii).

Denying the possibility to translate, or to state that (sometimes) no translation can ever be executed, is a matter of attitude, namely of arrogance, which may lead to a nationalist or chauvinist position regarding languages and translations. Steiner again critically remarks such kind of point of view:

The extreme 'monadist' position — we shall find great poets holding it—leads logically to the belief that real translation is impossible. What passes for translation is

\footnotetext{
${ }^{6}$ James S. Holmes, one of the leading figures in translation studies, said: 'Two further, less classically constructed terms have come to the fore in recent years. One of these began its life in a longer form, "the theory of translating" or "the theory of translation" (and its corresponding forms: "Theorie des Übersetzens", "theorie de la traduction"). In English (and in German) it has since gone the way of many such terms, and is now usually compressed into "translation theory"... It has been a productive designation, and can be even more so in future, but only if it is restricted to its proper meaning... The problem is not that the discipline is not a Wissenschaft, but that not all Wissenschaften [German for 'science' - the author] can properly be called sciences. Just as no one today would take issue with the terms Sprachwissenschaft [German, literally 'science of language' the author] and Literaturwissenschaft [German, literally 'science of literature' - the author], while more than a few would question whether linguistics has yet reached a stage of precision, formalization, and paradigm formation such that it can properly be described as a science, and while practically everyone would agree that literary studies are not, and in the foreseeable future will not be, a science in any true sense of the English word, in the same way I question whether we can with any justification use a designation for the study of translating and translations that places it in the company of mathematics, physics, and chemistry, or even biology, rather than that of sociology, history, and philosophy - or for that matter of literary studies' (Holmes 1988: 69-70).

7 'If we want our area of research to be given the consideration it deserves, more analyses are needed with a more theoretical and less anecdotal approach. I personally believe that DTS offers an ideal platform from which to launch this approach. For translation scholars, this catalogue of concepts is a heuristic tool that opens up new avenues for study, strengthens the theoretical component and allows the researcher to come up with substantial analyses' (Díaz Cintas 2004: 31). 'The acquisition of professional translation skills is often driven by prescriptivist judgements not always based on research. This often results in a tendency to anecdotalism and over-reliance on personal intuition and habits' (Pérez-González 2014: 94).
} 
a convention of approximate analogies, a rough-cast similitude, just tolerable when the two relevant languages or cultures are cognate, but altogether spurious when remote tongues and far-removed sensibilities are in question (p. 77).

Talking about theory always includes conceptions of methods and methodology that correspond to the foundations, terminology and intentions of a theory. Steiner argues not only against the partially misleading ideas of transformational and generative grammars, but he also deals with a certain methodological aspect of any theory, modelling. Admitting that modelling within a theory is one of the hardest endeavours a scholar might face, nevertheless modelling has its purpose and function that is to present a complicated network of processes, components, reasons in a clear, easy to follow form. However, a model stays a model, and from a methodological perspective, any model has to be proved by empirically grounding descriptions of experienced and elicited data. For this reason, Steiner says that

the danger is that formal linguistic models, in their loosely argued analogy with the axiomatic structure of the mathematical sciences, may block perception (p. 118).

Steiner sometimes sketches a more pessimistic picture about the responsibility, mission of language researchers and about the desiderata of the research work itself.

There are reasons for this lack. If we except the Moscow and Prague languagecircles, with their explicit association with contemporary poets and literature in progress, it can fairly be said that many modern analytic linguists are no great friends to language (p. 127).

Sadly, the tensions between (traditional) philology and mathematically organized linguistics are more actual than ever. Contradictions in understanding how to create theories and methodologies of research, animosities and prejudices towards the subjects of research of the other draw a dramatic picture of scholarly work on language and translation, which, eventually, may lead to an underrated value of linguistics and translation studies, compared with the so-called true sciences. It is a matter of fact that language in all its forms it can appear cannot be forced into a set of formulas.

It is very likely that the internalization of language and of languages in the human mind involves phenomena of ordered and ordering space, that temporal and spatiallydistributive hierarchies are involved. But no topologies of $n$-dimensional spaces, no mathematical theories of knots, rings, lattices, or closed and open curvatures, no algebra of matrices can until now authorize even the most preliminary model of the 'language-spaces' in the central nervous system (p. 308 - italics in original).

It was the mathematician Gottlob Frege of all those people who vehemently defended the character and essence of language against attempts to formalize and mathematize it because he stated that even both sides of an equation represent a different point of view of the same idea (cf. $2+5=3+4$ in Frege 
1984a: 137-8). Yet, there was more to Frege, especially sketching out a background for translation. ${ }^{8}$

Especially in Chapter Four of After Babel which is entitled The Claims of Theory, Steiner deals with the theory of translation by stating:

The literature on the theory, practice, and history of translation is large. It can be divided into four periods, though the lines of division are in no sense absolute ( $\mathrm{p}$. 248).

These four periods can be briefly described as:

1. from Cicero's famous precept not to translate verbum pro verbo and Horace's reiteration of this formula in the Ars poetica to Hölderlin's enigmatic commentary on his own translation from Sophocles (1804), with the main characteristic of immediate empirical focus;

2. is one of theory and hermeneutic inquiry by posing the nature of translation within the more general framework of theories of language and mind, as a methodological status of its own, away from the demands and singularities of a given text, mainly represented by A.W. Schlegel and W.v. Humboldt with extends to the mid of $20^{\text {th }}$ century;

3. the modern current by applying linguistic theory and statistics to translation, founding international bodies and journals concerned mainly or frequently with matters of translation proliferate, mostly influenced by work of Russian and Czech scholars and critics;

4. although the third period might be still in progress, another development can be detected, caused by differentiations in emphasis and subject since the 1960s, the study of theory and practice of translation has now become a point of contact between established and newly evolving disciplines, especially psychology, anthropology, sociology (pp. 248-260). ${ }^{9}$

Summarizing the history of translation studies and their theories, Steiner can pessimistically state:

\footnotetext{
${ }^{8}$ Concerning both the manifoldness within one language and of all languages in the world including processes of translation, Frege in his paper On Concept and Object [German 'Über Begriff und Gegenstand', original 1892] said: 'Nowadays people seem inclined to exaggerate the scope of the statement that different linguistic expressions are never completely equivalent, that a word can never be exactly translated into another language. One might perhaps go even further, and say that the same word is never taken in quite the same way even by men who share a language. I will not enquire as to the measure of truth in these statements; I would only emphasize that nevertheless different expressions quite often have something in common, which I call the sense, or, in the special case of sentences, the thought. In other words, we must not fail to recognize that the same sense, the same thought, may be variously expressed; thus the difference does not here concern the sense, but only the apprehension [Auffassung], shading [Beleuchtung], or colouring [Färbung] of the thought, and is irrelevant for logic. It is possible for one sentence to give no more and no less information than another; and, for all the multiplicity of languages, mankind has a common stock of thoughts' (Frege 1984b: 184).

${ }^{9}$ References to all mentioned scholars and researchers see Steiner.
} 
However, despite the rich history, and despite the calibre of those who have written about the art and theory of translation, the number of original, significant ideas in the subject remains very meagre. Ronald $\operatorname{Knox}^{10}$ reduces the entire topic to two questions: which should come first, the literary version or the literal; and is the translator free to express the sense of the original in any style and idiom he chooses (p. 251)?

Despite this unsatisfactory situation concerning a theory (or theories) of translation, Steiner nevertheless argues against attempts to establish ideas of untranslatability:

The argument against translatability is ... often no more than an argument based on local, temporary myopia.

Logically, moreover, the attack on translation is only a weak form of an attack on language itself (p. 263).

Steiner, of course, sees problems in translation, but instead of denying translation at all, he describes four stages concerning problems in translation by saying (1) 'not everything can be translated', (2) 'not everything can be translated now', (3) 'there are texts we cannot yet translate', (4) 'there are works not yet translatable by man, but potentially so, in a realm of perfect understanding and at the lost juncture of languages' (p. 262-3 - italics in original).

Moreover, Steiner offers a methodology of translation, admittedly only as a brief overview. Nevertheless, it is worth to pay attention to his outlines because they may serve as a foundation of a real methodology of translation, more or less independent from a constricting theoretical framework.

In brief: translation is desirable and possible. Its methods and criteria need to be investigated in relation to substantive, mainly 'difficult' texts. These are the preliminaries. Theories of translation either assume them or get them out of the way briskly, with greater or lesser awareness of logical pitfalls. But what, exactly, are the appropriate techniques, what ideals ought to be aimed for (p. 266)?

Although his reasoning is emotionally charged, one cornerstone of his statement seems to be clear: large corpora of 'difficult' texts should be the basis for figuring out the techniques of translation. Because all of that practicing is human work, mistakes and errors are possible, or as Steiner puts it, 'logical pitfalls' may occur. However, it is also up to the translator to gain and develop an awareness of such pitfalls not to extinct but to learn from them. After these introducing lines, Steiner sketches out (again) a triad of those 'methods and criteria':

The theory of translation, certainly since the seventeenth century, almost invariably divides the topic into three classes. The first comprises strict literalism, the word-byword matching of the interlingual dictionary, of the foreign-language primer, of the interlinear crib. The second is the great central area of 'translation' by means of

\footnotetext{
${ }^{10}$ Bibliographical information about Knox see Steiner, p. 251.
} 
faithful but autonomous restatement. The translator closely reproduces the original but composes a text which is natural to his own tongue, which can stand on its own. The third class is that of imitation, recreation, variation, interpretative parallel (p. 266 - bold emphasis by me).

However, this 'triad' might not be visualized as a triangle but as a flow chart representing the steps a translator will undertake to conduct a translation. Obviously, from step to step, the workload might rise while the translator more and more has to keep a balance between two basic aspects of the translation strategy, being appropriate to the things and being appropriate to the addressee ${ }^{11}$.

Figure 6. Flow Chart of Translation

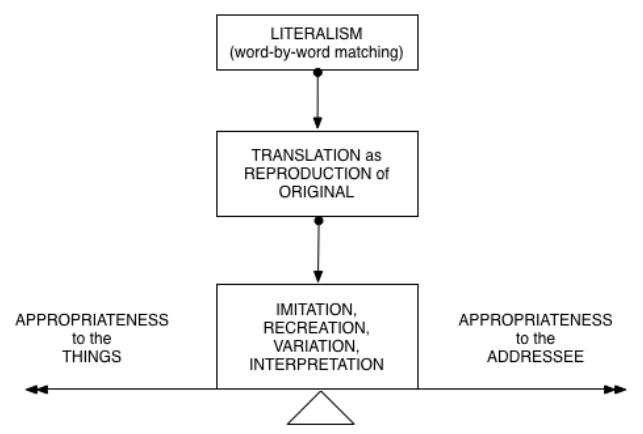

Source: visualized according to Steiner: 266

By referring to Roman Jakobson, Steiner focuses on terms like 'equivalence', 'rewording' and 'paraphrase' conducting a translation while especially 'rewording' and 'paraphrase' produce 'something more or less' than just applying instances of (lexical) equivalence. 'In consequence the mere act of paraphrase is evaluative,' because, according to Jakobson, 'on the level of interlingual translation, there is ordinarily no full equivalence between code-units' (p. 274). It is not only to take 'rewording' and 'paraphrase' as extensions to the components of the flow chart in Figure 6, it is another term used in the given quote that deserves our attention: 'evaluative', or 'evaluation' respectively. Executing a translation includes an evaluation of the source material and the target material as well, simply because the translator at least introduces himself/herself into the target material, his knowledge, experience, attitude, convictions etc.

On a more common, concluding statement, Steiner still—after giving outlines on translation theory concerning particular aspects - sees no chance to get a 'theory of translation' in the true and best sense of the term 'theory' by now and by far simply due to the insight that a theory of translation 'is necessarily a theory or, rather, a historical-psychological model, part deductive, part intuitive,

\footnotetext{
${ }^{11}$ Both aspects of appropriateness I discussed in a former paper because I think that translation is some sort of decision-making by finding a balance between being 'appropriate to the things and appropriate to the addressee... In this sense of appropriateness, any translation should be done, and doing so, terms like "source language/text/culture" and "target language text/culture" will become superfluous, sometimes, and may be replaced by the all-purpose-like terms used and defined by Genette, hypotext and hypertext' (Drößiger 2018: 275 - bold emphasis in original).
} 
of the operations of language itself' (p. 436) including the inseparable interplay of language and the mind. Thus, he points out quite pessimistically:

To summarize: we have no working model of the fundamental neurochemistry and historical aetiology of human speech. We have no anthropological evidence as to the causes of chronology of its thousandfold diversification. Our models of the learning process and of memory are ingenious but also of the most preliminary, conjectural kind. We know next to nothing of the organization and storage of different languages when they coexist in the same mind. How then can there be, in any rigorous sense of the term, a 'theory of translation' (p. 309)?

\section{Palimpsests, Metaphor, and Contiguity: Towards a New Conception of Translation}

Undoubtedly, Steiner can be taken as an exponent and a defender of the European idea. Following him, all our consciousness of Europe goes back to the ancient times of Greek culture, society, and language.

The totality of Homer, the capacity of the Iliad and Odyssey to serve as repertoire for most of the principal postures of Western consciousness ... point to a moment of singular linguistic energy (p. 22).

Because George Steiner wrote his book in the era of the Cold War, he naturally talks about the 'Western' culture and consciousness. However, nowadays against the background of the European Union, we shall feel free to interpret the 'Western' culture as a European culture. Later (p. 23) Steiner adds to the Greek the Hebraic influences simply due to the deep impact of the Old and the New Testament to European culture.

All in all, following Steiner's outlines, Greek language and culture has had the most important impact on our 'Western', i.e. European, culture simply by stating the enormous number of translations ever done from Greek into all those other languages we today may find in Europe (and of course not only there).

From Marsilio Ficino to Freud, the image of Greece, the verbal icon made up of successive translations of Greek literature, history, and philosophy, has oriented certain fundamental movements in Western feeling (p. 30).

Two additional aspects come into play, orientation and feelings. In other words, translation, that is in a wider sense language, gives orientation in the world. This does not automatically mean that orientation must be something that works on hierarchies, logical relations etc. It can also mean to get guidelines, suggestions, proposals for perceiving the world and for ruling our activities. Additionally, one thing should never be forgotten, the role of feelings and emotions in humans' perception of and acting in the world. 
This idea of Europe can be explained by looking at the following quote from After Babel, in which George Steiner outlines a phenomenon that might be interpreted as palimpsest:

A great part of Western art and literature is a set of variations on definitive themes ${ }^{12}$ (p. 24).

On the same page, Steiner calls an almost perfectly encompassing 'instrument' or 'feature' of the ancestors' languages (Greek, Hebrew, and Chinese) which can be taken as the foundation of the palimpsestic character of all achievements in languages, literature and arts of our 'Western' world: metaphor.

Why did certain languages effect a lasting grip on reality? Did Hebrew, Greek, and Chinese (in a way that may also relate to the history of writing) have distinctive resources? Or are we, in fact, asking about the history of particular civilizations, a history reflected in and energized by language in ways so diverse and interdependent that we cannot give a credible answer? I suspect that the receptivity of a given language to metaphor is a crucial factor (p. 24).

Thus, we might say that metaphor, or in terms of Lakoff and Johnson (1980) conceptual metaphor, is that explaining instance for telling what all languages will have in common. On the other hand, Steiner applies a conceptual metaphor to give more space to the idea of palimpsest without using the term 'palimpsest'.

The relations of a text to its translations, imitations, thematic variants, even parodies, are too diverse to allow of any single theoretic, definitional scheme ... But there can be no doubt that echo enriches, that it is more than shadow and inert simulacrum. We are back at the problem of the mirror which not only reflects but also generates light (p. 317).

Undoubtedly, it is a very individual characteristic of Steiner's writing to put not only several scholarly subjects and ideas into such a brief outline but also to use one (or more) linguistically determined cognitive concept to give reason to another one (or more). So, what is all included in this quote? First, there are

\footnotetext{
${ }^{12}$ Gérard Genette has once outlined this idea in a more common, all-encompassing way introducing the conceptual pair of terms called hypotext and hypertext. Deriving from the theoretical framework of transtextuality, Genette developed his special approach to what Steiner has called 'variations of definite themes'. However, Genette does not limit his comprehension of hypotext and hypertext neither to topics, themes, languages (in past or present) nor cultures and nations. Thus, Genette said: 'By hypertextuality I mean any relationship uniting a text B (which I shall call the hypertext) to an earlier text A (I shall, of course, call it the hypotext), upon which it is grafted in a manner that is not that of commentary. The use of the metaphoric "grafted" and of the negative determination underscores the provisional status of this definition. To view things differently, let us posit the general notion of a text in the second degree...: i.e., a text derived from another preexistent text... It may yet be of another kind such as text B not speaking of text A at all but being unable to exist, as such, without A, from which it originates through a process I shall provisionally call transformation, and which it consequently evokes more or less perceptibly without necessarily speaking of it or citing it' (Genette 1997: 5).
} 
'relations of a text to its translations' refers to intertextuality including text linguistics for example represented by Kristeva and Barthes; there are 'imitations', 'variants', 'parodies' which remind of Genette's palimpsests, which all goes hand in hand with Steiner's conceptional view to language and translation. Second, the conceptual metaphors introduced by Steiner bring some more facets of his approach to the fore. Thus, translation is not merely an echo, a shadow, a mirror, translation as a mirror is a creator of light, which finds its realization in perhaps enlightenment, reason, knowledge.

All that knowledge, reason, enlightenment must have their sources, their origin. But is it under question, discussion? Do we take all this for granted because of or due to the fact that we just belong to a 'Western' or 'European' cultural-language community? And is Steiner taking all this as a most natural thing?

We are so much the product of set feeling-patterns, Western culture has so thoroughly stylized our perception, that we experience our 'traditionality' as natural. In particular, we tend to leave unquestioned the historical causes, the roots of determinism which underlie the 'recursive' structure of our sensibility and expressive codes (p. 486).

The answer to be given is 'no'. Steiner in the entire book is fighting indifference towards reasons for all the actual status and situation we are living and acting in. Knowing our roots to almost every extent and realizing the equality of any human being is essential for comprehending the power of at last linguistic communication. Thus, Steiner sees in this universal equipment of the human race the ground for all specific derivations humans ever developed: historically, socially, linguistically, emotionally.

Given our common neurophysiological build, archetypal images, sign systems ought to be demonstrably universal. Those stylization and continuities of coding which we can verify are, however, culture specific. Our Western feeling-patterns, as they have come down to us through thematic development, are 'ours', taking this possessive to delimit the Graeco-Latin and Hebraic circumference (p. 486).

And the translator? Is he/she an enlightener, a Prometheus to us and for cultures and peoples? ${ }^{13}$ Anyway, a translator has to struggle with all the given amount of linguistic material, cultural references, ways to think, forms to satisfy the receivers' needs by finding a way to keep all in a balance between appropriateness to the things and appropriateness to the addressee, so as Steiner summarizes:

Where translation takes place at close cultural-linguistic proximity, therefore, we can distinguish two main currents of intention and semantic focus. The delineation of 'resistant difficulty', the endeavour to situate precisely and convey intact the 'otherness' of the original, plays against 'elective affinity', against immediate grasp

\footnotetext{
${ }^{13}$ A translator (like an author) is a liar. See Ursula K. LeGuin's introduction to her novel The Left Hand of Darkness: http://theliterarylink.com/leguinintro.html
} 
and domestication. In perfunctory translation these two currents diverge. There is no shaping tension between them, and paraphrase attempts to mask the gap. Good translation, on the contrary, can be defined as that in which the dialectic of impenetrability and ingress, of intractable alienness and felt 'athomeness' remains unresolved, but expressive (p. 412-13).

Although Steiner only talks about such a 'close cultural-linguistic proximity' which may serve the idea of Europe, although, it might be possible to apply this statement also for all other cultural-linguistic distances in case of translations.

Moreover, there is one instrument of language and thinking that goes far deeper towards finding the commons between all those languages we nowadays may count on Earth: metonymy that grounds on contiguity. Thus, it makes sense to start discussing the concept of contiguity by an all-encompassing idea which sets the foundation for comprehending contiguity:

The accidental, historically moulded differences between tongues are, no doubt, formidable. But underlying these there are principles of unity, of invariance, of organized form, which determine the specific genius of human speech. Amid immense diversities of exterior shape, all languages are 'cut from the same pattern' (p. 98).

Such 'underlying principles' are what contiguity is meant to be, that is the basic form and way we think, act, behave, and feel. The differences are a matter of perspective ${ }^{14}$ and a matter of 'exterior shape'. The former can be understood as the way we may approach a certain concept, term, or idea to process it, to comprehend it, to make it applicable for our everyday life. The latter concerns the outer ('exterior') form in which we act, speak, behave. Because the principle of contiguity and its linguistically appearing form we call 'metonymy' are so deeply embodied $^{15}$ in all humans, this basic human cognitive set-up is very often overlooked by researchers of language and mind. Nevertheless, following Steiner's idea of languages being 'cut from the same pattern', we can take this as the first and ground setting instance of contiguity. Subordinate or derived from this ground setting instance of contiguity are several, mostly language specific, instances of it which found their manifestation in certain forms:

Differences of stress, organized sequence, relations of hierarchy as between the general and the particular or the sum and the part, these are the counters of reason from which all languages develop (p. 102).

\footnotetext{
${ }^{14}$ See above footnote \# 5 .

${ }^{15}$ 'Metonymy is a more deeply embedded and ingrained capability of the human mind than classical approaches may tell. The cognitive turn in linguistics changed the point of view to the interaction between language and mind, thus, new approaches to understand what metonymy is might come into life...This leads to a comprehension of metonymy as a common, probably universal capability of human language and thinking - beyond the boundaries of languages and culture' (Drößiger 2015: 8).
} 
Language typology ${ }^{16}$ is a good example for dealing with these differences between languages. However, all typological endeavours are directed to the surface, the 'exterior shape' of languages. Digging deeper, we easily become aware of those commons between languages, called contiguity.

Steiner sees a widely spread richness in the European culture because of the immense work translators did within more than the last two centuries by calling this state of affairs

the created contemporaneity of ancient and modern and the unified diversitycoherent as are the facets of a crystal — of the European community as they derive from two hundred years of translation (p. 261).

The term 'European community' appears here, as far as I noticed, for the first time in After Babel, thus, we might say now that Steiner indeed sees Europe as a community despite or because of its inner diversity and contradictions. Yet, this community can stand together, however not exclusively, caused by a certain part of work done by linguists and translators who brought literacy and knowledge of all kind to every nation and ethnic group of Europe.

\section{Instead of Conclusions: An Outlook}

Summarizing this entire article can be done by quoting Steiner for a last time. In the section called Afterword, he points out:

To a greater or lesser degree, every language offers its own reading of life. To move between languages, to translate, even within restrictions of totality, is to experience the almost bewildering bias of the human spirit towards freedom. If we were lodged inside a single 'language-skin' or amid very few languages, the inevitability of our organic subjection to death might well prove more suffocating than it is (p. 497).

At first sight, Steiner's words sound pessimistic and may evoke a feeling of helplessness. However, if we notice the gentle allusion to W.v. Humboldt's cosmopolitan attitude towards mankind while saying that 'every language offers its own reading of life', we might feel free to take the entire quote as a paraphrase for that one all-encompassing capability of the human thought and thus for all languages which we may call 'contiguity', then our view to language and translation will probably change from confusion to confidence in men. In doing so, we have good reason for it since 'to experience the almost bewildering bias of the human spirit towards freedom' expresses all the above outlined interplay of language, community and thought. In all that possible manifoldness of human activities to eventually gain freedom, a single, universal idea rules all our endeavours, that is language which shall be a guarantor of freedom.

\footnotetext{
${ }^{16}$ Moravcsik points out that linguistic typology is 'the study of the similarities and differences among languages that hold across genetic, areal, and cultural boundaries' (2013: ix).
} 


\section{References}

Cruse A (2012) A Glossary of Semantics and Pragmatics. Edinburgh: University Press.

Díaz Cintas J (2004) In search of a theoretical framework for the study of audiovisual translation. In Topics in Audiovisual Translation, P Orero (ed), 21-34 Amsterdam. Philadelphia: Benjamins.

Drößiger HH (2015) Mehr über Metonymie [More about Metonymy]. In Inostrannye jazyki v vysšej škole. Naučnyj žurnal 3(34): 8-14. https://bit.ly/32tvHYC.

Drößiger HH (2018) On Palimpsests: How to Use this Concept for Translation Studies. In Memoriam Gérard Genette (1930-2018). Athens Journal of Philology 5(4): 261-283.

Frege G (1984a) Function and Concept (Lecture at the January 9, 1891 meeting of Jena's Society for Medicine and Natural Science); translation by P Geach. In Collected Papers on Mathematics, Logic, and Philosophy, B McGuinness (ed), translated from the German collection by M Black, V H Dudman, P Geach, H Kaal, E-H W Kluge, B McGuinness, and R H Stoothoff. Oxford: Basil Blackwell, 137-156. https://bit.Ly /2QqIJ3S.

Frege G (1984b) On Concept and Object. In Collected Papers on Mathematics, Logic, and Philosophy B McGuinness (ed), translated from the German collection by $\mathrm{M}$ Black, V H Dudman, P Geach, H Kaal, E-H W Kluge, B McGuinness, and R H Stoothoff. Oxford: Basil Blackwell, 182-194. https://bit.ly/3hvUp15.

Genette G (1997) Palimpsests. Literature in the second degree. Lincoln. London: University of Nebraska Press [French original 1982].

Geeraerts D (2010) Theory of Lexical Semantics. Oxford: University Press.

Graumann CF, Kallmeyer W (2002) Perspective and perspectivation in discourse. An introduction. In Perspective and Perspectivation in Discourse, CF Graumann, W Kallmeyer (eds), 1-11. Amsterdam: John Benjamins.

Holmes JS (1988) The Name and Nature of Translation Studies. In: Translated!: Papers on Literary Translation and Translation Studies, 66-80. Amsterdam: Rodopi. [Original 1975].

Lakoff G, Johnson M (1980) Metaphors We Live By. Chicago: The University of Chicago Press.

LeGuin U (nd) Introduction to The Left Hand of Darkness. Retrieved from https://bit.ly/ 2FQeHUS.

Moravcsik EA (2013) Introducing Language Typology. Cambridge: University Press.

Ogden CK, Richards IA (1930) The Meaning of Meaning. Third edition revised. London: Kegan Paul, Trench, Trubner \& Co. [Original 1923].

Pérez-González L (2014) Audiovisual Translation. Theories, Methods and Issues. London. New York: Routledge.

Snell-Hornby M (2006) The Turns of Translation Studies: New paradigms or shifting viewpoints? Amsterdam. Philadelphia: Benjamins.

Steiner G (1998) After Babel: aspects of language and translation, $3^{\text {rd }}$ ed. Oxford: University Press. 